Research Article

\title{
Estimation of Quercetin and Rutin Content in Hyouttunia cordata and Centella asiatica Plant Extracts Using UV-Spectrophotometer
}

\author{
Arky Jane Langstieh ${ }^{1}$, Julie Birdie Wahlang ${ }^{2}$, Clarissa Jane Lyngdoh ${ }^{3}$, Ibaphylla Jaba ${ }^{4}$, Chayna Sarkar ${ }^{5}$, D.K. Brahma \\ 1. Technical Assistant, Department of Pharmacology, Neigrihms, Shillong, India- 793018. \\ 2. Assistant Professor, Department of Pharmacology, Neigrihms, Shillong, India- 793018 \\ 3. Assistant Professor, Department of Microbiology, Neigrihms, Shillong, India- 793018. \\ 4. Pharmacist, Department of Pharmacology, Neigrihms, Shillong, India- 793018. \\ 5. Professor, Department of Pharmacology, Neigrihms, Shillong, India- 793018. \\ 6. Associate Professor, Department of Pharmacology, Neigrihms, Shillong, India- 793018. \\ *Corresponding author's E-mail: juliewahlang@gmail.com
}

Received: 14-11-2021; Revised: 26-11-2021; Accepted: 04-12-2021; Published on: 20-12-2021.

\section{ABSTRACT}

Flavonoids are secondary plant metabolites normally found as pigmented compounds in plants. Quercetin and rutin are two important and commonly found flavonoids in nature and exhibit wide pharmacological effects such as antioxidant, anticarcinogenic, antiviral, anti-inflammatory, antidiabetic, and hepatoprotective activities as well as antimicrobial activity. In this study, quercetin and rutin content is being quantified in the plant extracts of Centella asiatica and Houttuynia cordata and considerable amounts of these two flavonoids were depicted. A single beam UV - Spectrophotometer was used to measure the absorbance of the standard as well as test solutions. Calibration curves were constructed for standard quercetin and rutin in such a way that $\mathrm{x}$-axis denotes concentration and the $y$-axis denotes the absorbance. The calibration curves showed linearity at concentrations $5-25 \mu \mathrm{g} / \mathrm{ml}$ of quercetin and rutin respectively with a good correlation coefficient $(r)$ of 0.99 for both the curves. The absorbance of the two test extracts was obtained from the calibration curve and respective concentrations of quercetin and rutin for the two extracts were calculated. The amount of quercetin and rutin present was expressed as Total Flavonoid Content (TFC) i.e. the amount of the flavonoid in $\mu \mathrm{g}$ present per mg of the respective plant extract. The quercetin content in both the plant extracts was found to be more (315.8 in Houttuynia cordata; 487.6 in Centella asiatica) than the content of rutin (152.2 in Houttuynia cordata; 171.0 in Centella asiatica).

Keywords: Flavonoids, Quercetin, Rutin, UV- spectrophotometer, Calibration.

QUICK RESPONSE CODE $\rightarrow$

DOI:

10.47583/ijpsrr.2021.v71i02.021

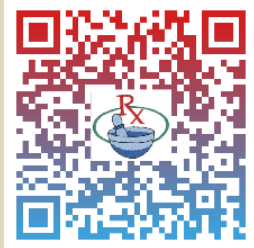

DOI link: http://dx.doi.org/10.47583/ijpsrr.2021.v71i02.021

\section{INTRODUCTION}

F

lavonoids are also known to be the secondary plant metabolites found in several parts of a plant. These falls under an important class of compounds responsible for plant growth and its protective mechanism. ${ }^{1}$ Some of the important and common flavonoid compounds found in nature are quercetin, rutin, catechin, epicatechin, myricetin, anthocyanidins, and kaemferol. Chemically, they are polyphenolic compounds with low molecular weight characterized by their flavan nucleus and acts as the bioactive compounds in various fruits, vegetables, and certain beverages. Flavonoids are normally found as pigmented compounds. ${ }^{2}$ Biologically, these chemical entities are responsible for many biological defense processes in the human body such as protecting against cerebral ischemic disease and other cerebroprotective effects mainly because of its many pharmacological activities like antioxidant, anti- inflammatory, and anti-platelet aggregatory. ${ }^{3}$ Studies conducted in analyzing their pharmacological involvement have shown that these polyphenols have efficient inhibitory activity against various bacteria as well as fungi. The antimicrobial activity of a plant has been linked to higher flavonoid content present. ${ }^{4}$ Flavonoids have also been used extensively in Argentine folk medicines as well as in Chinese ancient treatment for treating infectious diseases and infected oral wounds. ${ }^{5}$ Besides being known as potential antimicrobials, these plant compounds are also known to exhibit other very important protective activities include anticarcinogenic, antiviral, antiinflammatory, antidiabetic, antiulcer, and hepatoprotective activities. The antioxidant property and radical scavenging activity and metal chelating property have very much attributed to their wide pharmacological activities. $^{2}$ Due to their vast therapeutic efficacies, the estimation of the flavonoid content is therefore desirable to assess the activity of these plant extracts. This study is a lateral study to the already studied antimicrobial effects of our plant extracts of interest. ${ }^{4}$ Hence, estimation of the content of phytoactive constituents present in these plant extracts might help in the elucidation of mechanisms of antimicrobial activity of Centella asiatica and Houttuynia cordata.

Centella asiatica L. is a widely known herbal plant belonging to the Mackinlayaceae family. Other known 
names are Brahmi or Mandookparni. Its use in the treatment of various disorders has been reported since olden times such as brain tonic and mental diseases. The antimicrobial property has also been reported in our recent study besides other reported anticancer and wound healing activities. Houttuynia cordata Thumb. which is found in most regions of eastern Asia has also been known for its immune-stimulating property. Our recently concluded study on antimicrobial effects of Centella asiatica and Houttuynia cordata on multidrug-resistant isolates showed promising results of these extracts as antimicrobials which can be attributed to the presence of flavonoids in these plants extracts. ${ }^{4}$

\section{MATERIALS AND METHODS}

The method of estimation of quercetin was according to the procedure mentioned by Patil et al., $2012^{6}$ and estimation of rutin was followed according to Chaudhari et al., 2014. ${ }^{3}$

\section{Apparatus}

A single beam UV- spectrophotometer (Spectro nano-G Photometer) attached to computer software (UV-Vis analyst) was used in measuring the absorbance and determining the concentration.

\section{Materials}

The plant extracts of Centella asiatica (CA) and Houttuynia cordata $(\mathrm{HC})$ which was already extracted and stored in a refrigerator at $4{ }^{\circ} \mathrm{C}$ in the Dept. of Pharmacology, NEIGRIHMS, Shillong (voucher specimen no AKY/003) was used. ${ }^{4}$ Standard quercetin and rutin were purchased from Oxford laboratory, India. Methan0.ol and ethanol were procured from S.D. Fine Chem Ltd., India.

\section{Methods}

\section{Preparation of stock solution of quercetin and rutin}

Quercetin $(100 \mu \mathrm{g} / \mathrm{ml})$

The stock solutions of quercetin $(100 \mu \mathrm{g} / \mathrm{ml})$ were prepared by dissolving $10 \mathrm{mg}$ of quercetin in sufficient quantity of ethanol and then the volume was adjusted to $100 \mathrm{ml}$.

\section{Rutin $(100 \mu \mathrm{g} / \mathrm{ml})$}

The stock solutions of rutin $(100 \mu \mathrm{g} / \mathrm{ml})$ were prepared by dissolving $10 \mathrm{mg}$ of rutin in a sufficient quantity of methanol and then adjusting the volume to $100 \mathrm{ml}$.

\section{Preparation of sample solutions of plant extracts}

\section{For quercetin estimation}

The sample solution of $\mathrm{HC}$ and CA was prepared by dissolving $10 \mathrm{mg}$ of the respective extracts in $100 \mathrm{ml}$ of ethanol. Further dilution was done to obtain a final concentration of $50 \mu \mathrm{g} / \mathrm{ml}$ of HC and CA separately.

\section{For rutin estimation}

A sample solution of $\mathrm{HC}$ and CA was prepared by dissolving $10 \mathrm{mg}$ of the respective extracts in $100 \mathrm{ml}$ of methanol and further dilution was done to obtain a final concentration of $50 \mu \mathrm{g} / \mathrm{ml}$ of HC and CA separately.

\section{Calibration curve}

For obtaining the calibration curves of quercetin and rutin, series of dilutions was prepared from both the stocks respectively, in such a manner that concentrations of 5 $\mu \mathrm{g} / \mathrm{ml}, 10 \mu \mathrm{g} / \mathrm{ml}, 15 \mu \mathrm{g} / \mathrm{ml}, 20 \mu \mathrm{g} / \mathrm{ml}$ and $25 \mu \mathrm{g} / \mathrm{ml}$ of quercetin and rutin were obtained. The absorbance was measured at $256 \mathrm{~nm}$ using ethanol as a blank for quercetin and the same was done for rutin using methanol as blank at $257 \mathrm{~nm}$. The concentration on the $x$-axis and absorbance on the $y$-axis was plotted accordingly for quercetin (Fig. 1) and rutin (Fig. 2).

\section{Total Flavonoid Content (TFC)}

The total content of quercetin and rutin present in both the plant extracts of $\mathrm{HC}$ and CA was calculated accordingly from the respective calibration curve and expressed as TFC i.e. the amount of quercetin $(\mu \mathrm{g})$ or rutin $(\mu \mathrm{g})$ present per $\mathrm{mg}$ of the extract $(\mu \mathrm{g} / \mathrm{mg})$.

\section{RESULTS AND DISCUSSION}

\section{Calibration curve}

The calibration curves of quercetin (Fig. 1) and rutin (Fig. 2) were obtained and both the curves showed linearity in the concentration range of $5-25 \mu \mathrm{g} / \mathrm{ml}$ with the correlation coefficient $(r)$ value corresponding to 0.99 .

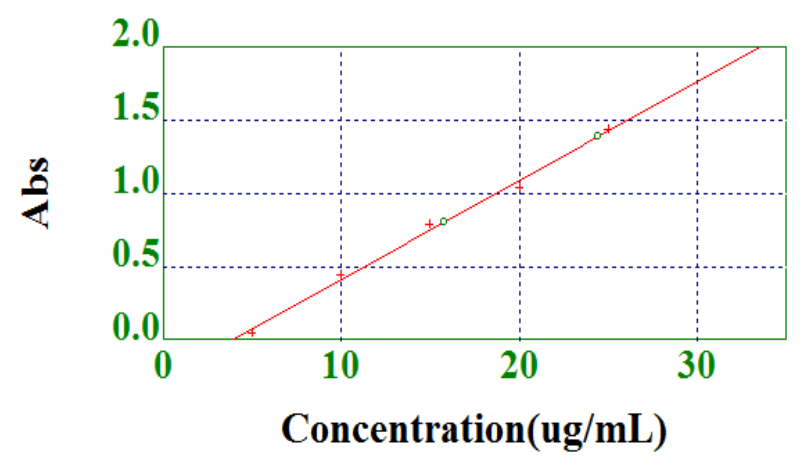

$$
+=\text { Quercetin; } \mathrm{O}(\text { First })=\mathrm{CA} ; \mathrm{O}(\text { Second })=\mathrm{HC}
$$

Figure 1: Calibration curve of Quercetin.

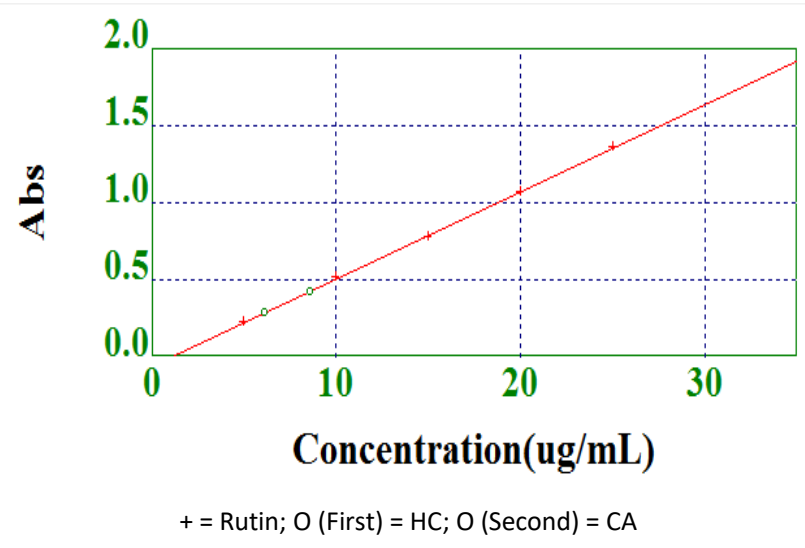

Figure 2: Calibration curve of Rutin. 


\section{Total flavonoid content (TFC)}

The Total Flavonoid Content ( $\mu \mathrm{g}$ of quercetin or rutin present per mg of extract) present in Houttuynia cordata and Centella asiatica is shown in Table 1. The amount of flavonoid detected in the extract of $\mathrm{HC}$ is composed more of the quercetin compound than that of rutin. The same result was seen in the case of the amount of total flavonoid content in CA where the amount of quercetin is more than that of rutin.

Table 1: Quercetin and rutin content in Houttuynia Cordata and Centella Asiatica

\begin{tabular}{|l|c|c|}
\hline Plant extract & Flavonoid & $\begin{array}{c}\text { TFC }(\mu \mathrm{g} / \mathrm{mg} \text { of } \\
\text { extract) }\end{array}$ \\
\hline $\begin{array}{l}\text { Houttuynia } \\
\text { cordata }\end{array}$ & Quercetin & 315.80 \\
\hline Centella asiatica & Rutin & 152.2 \\
\hline & Quercetin & 487.6 \\
\hline
\end{tabular}

\section{CONCLUSION}

Quercetin and rutin have been extensively studied for their beneficial health effects such as antioxidant, antimicrobial, antifungal, anticancer, and various other health benefits. ${ }^{7}$ A study reporting the effect of quercetin 3-rhamnoside, extracted from Houttuynia cordata, showed that this particular phytoconstituent can inhibit the replication of the influenza virus and also exhibit greater efficacy than the antiviral drug, Oseltamivir. ${ }^{8}$ Among all the flavonoids components found to be present in Houttuynia cordata, quercetin has shown to possess the most antiviral activity against strains of viruses like hepatitis virus and dengue virus, thereby supporting the possibility of exploiting this compound or its resources for the treatment of these viral infections as well as other viral indications as in the case of corona viruses and dengue viruses. ${ }^{9}$.

Houttuynia cordata and Centella Asiatica plant extracts in our study also showed the presence of the flavonoids, quercetin, and rutin, but the amount of quercetin present exceeds more than that of rutin in both the plant extracts. The considerable presence of these bioactive molecules in our extract shows that Houttuynia cordata and Centella Asiatica can be used as alternative sources for the treatment of diseases where reduced use of antibiotics is required and to further tackle the problem of antibiotic resistance to provide a safe and sustainable opportunity for the health and development of an individual. Since, these plants are also being consumed raw as salad in the northeastern part of India and other parts of Asia like
Japan and Korea. ${ }^{10,11}$ Our plants of interest might serve as an important source of these active molecules. The estimation of the quantity of these molecules present in these extracts might therefore serve as an important tool in determining the mechanisms and the role played by each phytoactive constituent through which these plants exert their overall beneficial effects on the health and wellbeing of an individual.

\section{REFERENCES}

1. Panche AN, Diwan AD, Chandra SR. Flavonoids: an overview. Journal of nutritional science. 2016;5:21-26.

2. Bose S, Sarkar D, Bose A, Mandal SC. Natural flavonoids and its pharmaceutical importance. The Pharma Review. 2018:14:61-75.

3. Chaudhari SP, Bangar JV, Akuskar GK, Ratnaparkhi MP. Development and validation of UV spectrophotometric method for simultaneous estimation of rutin and quercetin in niosome formulation. Der Pharmacia Lettre. 2014;6(3): 271-6.

4. Lyngdoh CJ, Wahlang JB, Langstieh AJ, Hadem KLH, Bora I, Lahon J, Sabhapandit D. Antimicrobial Activity of Aristolochia tagala Cham. Centella asiatica Linn. Houttuynia cordata Thunb. on Multi-Drug Resistant Clinical Isolates. International Journal of Pharmaceutical Sciences Review and Research. 2020;64(2): 76-81.

5. Cushnie TT, Lamb AJ. Antimicrobial activity of flavonoids. International journal of antimicrobial agents. 2005 Nov 1;26(5):343-56.

6. Patil SJ, Salunkhe VR. Simultaneous Estimation of Curcumin and Quercetin in Ayurvedic Proprietary Medicine by UV Spectrophotometry. International Journal of Research in Ayurveda \& Pharmacy. 2012 Mar 1;3(2):50-55.

7. Tungmunnithum D, Thongboonyou A, Pholboon A, Yangsabai A. Flavonoids and other phenolic compounds from medicinal plants for pharmaceutical and medical aspects: An overview. Medicines. 2018 Sep;5(3):93-99.

8. Choi HJ, Song JH, Park KS, Kwon DH. Inhibitory effects of quercetin 3-rhamnoside on influenza A virus replication. European Journal of Pharmaceutical Sciences. 2009 Jun 28;37(3-4):329-33.

9. Chiow KH, Phoon MC, Putti T, Tan BK, Chow VT. Evaluation of antiviral activities of Houttuynia cordata Thunb. extract, quercetin, quercetrin and cinanserin on murine coronavirus and dengue virus infection. Asian Pacific journal of tropical medicine. 2016 Jan 1;9(1):1-7.

10. Kumar M, Prasad SK, Hemalatha S. A current update on the phytopharmacological aspects of Houttuynia cordata Thunb. Pharmacognosy Reviews. 2014 Jan;8(15):22-28.

11. Chandrika UG, Kumara PA. Gotu Kola (Centella asiatica): nutritional properties and plausible health benefits. Advances in food and nutrition research. 2015;76:125-57.

Source of Support: The author(s) received no financial support for the research, authorship, and/or publication of this article.

Conflict of Interest: The author(s) declared no potential conflicts of interest with respect to the research, authorship, and/or publication of this article.

For any question relates to this article, please reach us at: editor@globalresearchonline.net

New manuscripts for publication can be submitted at: submit@globalresearchonline.net and submit_ijpsrr@rediffmail.com 